\title{
Influence of Community Design on Line User Behaviours in Cross-Border E-Commerce
}

\author{
Yu-Ping WU ${ }^{a,{ }^{*}}$, Hong JIN ${ }^{b}$, Chih-Hsuan HUANG ${ }^{c}$ \\ No. 8 Yang Qiaohu Road, Jiangxia, Wuhan, P. R. China, Collaborative Innovation Center of China \\ Pilot Reform Exploration and Assessment-Hubei Sub-Center, Hubei University of Economics

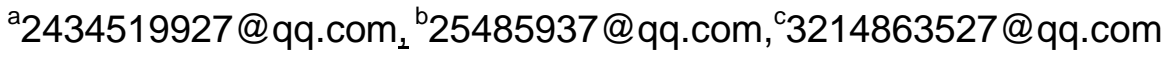 \\ ${ }^{*}$ Corresponding author
}

Keywords: Interactivity, Social presence, Common identity attachment, Common bond attachment, Cross-border E-commerce.

\begin{abstract}
With the rapid development of the cross-border online shopping market, virtual experience has increasingly been the object of study in recent years. A growing number of studies have reported the positive effect that virtual experience can have on a user's mood. However, few studies have investigated the influence of the mechanism of virtual experience on users' identity and bond. To compensate for this research gap, this study aims to evaluate consumers' virtual experience by examining the flow state in online shopping environment. To provide a deeper understanding of how cross-border e-commerce accounts can effectively engage consumer, this study examines the social aspects of the cross-border e-commerce context by focusing on social presence. This study investigates the relationships among interactivity, perceived value, social presence, common identity and common bond. Though an experiment with 908 Ali express users, the study finds that all hypotheses are supported. The results demonstrate the importance of affective commitment as a relationship enhancer, and identify managerial implications for customer commitment to cross-border e-commerce accounts.
\end{abstract}

\section{Introduction}

More and more Chinese consumers enjoy internet shopping because of strong economic growth and rapid internet penetration. Furthermore, they are enthusiastic buyers of foreign products using foreign online retailers. China's cross-border e-commerce is a new pattern of cross-border trade which takes electronic as means. The rapid development of cross-border trade is inseparable from promoting e-commerce platform. Currently, there are some platform which could provide service of cross-border e-commerce in China, including Amonza, ebay and Ali express. It has grown at the exceptionally fast rate of 74.8 per cent annually from 2011 and reached about US\$600bn market size according to the China Internet Network Research Center (2016). In a recent survey by Nielsen, 32 per cent Chinese respondents had experienced purchasing overseas goods online, and a PayPal survey found cross-border shopping will grow to 130 million consumers by 2018, including 36 million from China. Alibaba started operating www.tmall.hk in February 2014, which is a business-to-customer (B2C) model haitao business. Amazon.cn also started its haitao business in November 2014. Gmarket.co.kr initiated haitao service from 2013 and invested aggressively because of rapid sales growth in 2013. A number of studies have demonstrated that a user's mood and loyalty can be enhanced through the virtual environment [1]. Jung (2011) [2] noted that the experience of presence affects users continued use of social virtual worlds. Moreover,Plante et al. (2003) [3] investigated how virtual reality technology may promote users' mood of exercise.

Cross-border e-commerce creates new market spaces and provides differentiated values for Chinese customers. Building and managing good relationships with Cross-border e-commerce users have become increasingly critical to business's marketing efforts and sustainability. Customers' perceived value is often deemed as the key factor most drastically influencing the behavioral outcome in the course of decision-making of purchase. The customers' assessment before purchase, continual use after purchase or the value perceived via customers will all further influence the future purchase 
intention. Therefore, the higher value perceived by the customer is, the higher expectation will produce in customers, and the purchase intention will also be stronger. In the past research, few scholars discuss about the users' perceived value of using technology products. However, in the context of using cross-border e-commerce, customers' perceived value will provide some key successful factors to obtain the users' attention and promote to continue their downloading or purchase.

Our study differs from previous studies in the following respects. First, in a cross-border e-commerce content, Interactivity and perceived value have also been found to be a significant antecedent of increased interaction and gratification of social connection need. Second, social presence, which has been shown to play an important role in providing satisfying interactions and relationship building in computer-mediated communication. We adopt social presence formation to examine the effect of those communication characteristics on the formation of social presence. Third, previous literature on cross-border e-commerce primarily focused on Western countries, whereas we include Asian countries in our study. It can help us better understand how well-managed communications leveraged by cross-border e-commerce characteristics can lead to engaging and sustained relationships between cross-border e-commerce accounts and users.

\section{Conceptual Framework}

\section{Interactivity}

Interactivity is the difference in communication between tradition media and the internet, and is a new variable that may influence service quality [4]. Steuer (1992) [5] suggested that interactivity refers to the level and type of content that encounters in real-time adjustments to the virtual environment. Furthermore, many studies have adopted the telepresence view in analyzing virtual experience; for instance, Animesh et al. (2011) [6] studied the relationship between person and computer interactivity and the purchase of virtual goods in online games, and Suntornpithug and Khamalah (2010) [7] studied the relationship between person and computer interactivity and online purchasing.

According to Hoffman and Novak (1996) [8], studies of interactivity have divided virtual interaction into two forms: interpersonal interaction and machine interaction. Interpersonal interaction is concerned with dialogue, communication and the exchange of information through websites, such as forums. Machine interaction is the degree to which users can participate in a website through browsing, searching, or providing feedback. The blog platform facilitates a very high level of interpersonal interaction that allow users to express their opinions and create dialogues, and to interact with others by contacting, making friends, communicating and information exchange [9].

\section{Perceived Value}

Sweeny and Soutar(2001) [10] thought that perceived value is the satisfaction coming from different customers. In respect of the customers' assessment in the value of products or service, on one hand, the customers' expected performance and money value for products or service are required to be considered, on the other hand, the sense of pleasure and fun produced or brought by customers' use of products or service, as well as the socialidentity and sense of belonging conveyed by products or service to others are required to be included. This research adopted the four values proposed by Sweeny and Soutar (2001) [10] to discuss the customers' opinions of function value, emotional value, social value and money value in the context of using the cross-border e-commerce account program, which will be used as the basis to measure customers' perceived value in this study.

\section{Social Presence}

Social presence theory focuses on the degree to which communicating parties in a mediated environment perceive one another in terms of being a "real person" [11]. Social presence is the extent to which a medium allows users to experiences others as being psychologically present.Social presence can help overcome these potential problems by increasing peer connections. When 
individuals are connected they are more likely to attend more deeply to messages and to see the value of the messages and the ideas and contributions of others [12].

In the cross-border e-commerce context, social presence has been employed to evaluates the relational aspects between users and websites. Creating a virtual shopping experience that will entice the masses must engage the cognitive and social sides of the customers.

\section{Common Identity Attachment and Common Bond Attachment}

The question of how online community design can trigger certain user behavior has attracted considerable attention in marketing research, especially in terms of describing brand community member behavior $[13,14]$. However, the literature provides little theory-based knowledge to predict how or why specific policies and features make online communities successful in engaging and retaining members [15]. An exception is Ren et al.'s (2007) [16] comprehensive framework based on the social psychological theories of common identity and common bonds. Common identity and common bond attachment refer to the different reasons for being in a community, that is, because users like a community as a whole (identity-based attachment), or because they like individuals in a group (bond-based attachment). Specifically, common identity attachment implies that members feel a commitment to an online community's purpose, whereas common bond attachment implies that members feel socially and emotionally attached to specific community members. Hence, if community members experience common identity attachment, belonging to this community is very important to them. They feel good when being described as a member of this community, and they feel a strong attachment to the com- munity as a whole. If community members experience common bond attachment, they primarily feel very close to specific members of this community.

Recently, Ren et al. (2012) [15] found that online community features intended to foster identity-based attachment have stronger effects on participation and retention than features intended to foster bond-based attachment. Furthermore, the authors found that removing off-topic messages increases members' information benefits at the expense of their opportunities to develop online relationships. While these results provide support for several tenets of Ren et al.'s (2007) [16] model, most of the original specified relationships remain re- search hypotheses. Specifically, the relationship between identity-based and bond-based attachment and their numerous antecedents, as well as the mediating role of attachment types for explaining user behavior, have not yet been empirically evaluated as an entire model.

In this research, we examine two levels of attachment: identity-based attachment and bond-based attachment to individual member behavioral. Following the review by Ren et al. (2007) [16], we summarize these antecedents next and present our hypotheses of how their implementations can increase attachment in cross-border e-commerce communities.

\section{Continuance Intention}

According to Bhattacherjee (2001) [17], user who were more satisfied with their experience of online SNS would have a higher level of continuance intention. If the individual user feels that an information system is useful, he or she will think positively about it [18]. Online social network users sense usefulness since they can get information and knowledge from other users or the SNS system service, and they can connect with others and know more people through the SNS system [19].Some previous studies gave evidence that SNS users' usefulness perception can positively influence their intention to use the system and their satisfaction with online SNS [19,20] Furthermore, studies on post-adoption behaviors have verified the IS continuance theory in the online context, e.g., the online brokerage context and internet-based learning context. Considering the strong theoretical foundation and robust empirical results, we employ IS continuance theory as the base research model.

\section{Hypothesis Development}

\section{The Effect of Interaction on Social Presence}

Social presence theory [21] suggests that the degree of social presence in the medium determines how 
sociable of a medium. Some social networking sites emphasize the presence of other people's involvement in order to facilitate communication through the Internet.

For example, the presence of others can be seen by the News Feed function, as it keeps tracks of friends' actions once they log in the online social network. Non-users can also seek the presence of their friends in an online social network through the Join Invitation function. A high perceived social presence would have a greater impact influencing individuals to join and to continue using an online social networking site, since individuals tend to select the medium that they perceive to have the highest social presence [22]. Therefore:

\section{H1a: Machine Interaction will positive influence social presence.}

\section{H1b: Interpersonal Interaction will positive influence social presence.}

\section{The effect of Perceived value on Social Presence}

Perceived value is the essential result of marketing activates and is a first-order element in relationship marketing. It is understood as a construct configured by two parts, one of benefits received (economic, social and relationship) and another of sacrifices made (price, time, effort, risk and convenience) by the customer. Transferring the experiential view to the study of the perceived value construct, two conclusions can be drawn. Firstly, the view of perceived value as a cognitive variable is partial, since it is necessary to incorporate the affective component. Secondly, social presence is the importance of the component in which the technology enables to create an environment in which they feel is warm, personal, sociable, and active. Social presence is known to shape people's physiological and psychological responses to objects in their environment. Such person interactivity in a cross-border e-commerce account give users a feeling that good experiences of consumption and helps form a sense of social presence within the cross-border e-commerce account. Thus, we hypothesize the following:

H2a: Functional value will positive influence social presence.

H2b: Emotion value will positive influence social presence.

H2c: Social value will positive influence social presence.

H2d:Monetary value will positive influence social presence.

\section{Relationship between Social Presence and Attachment}

According to the social identity theory, identification with a social group is mainly derived from the group's ability to fulfill its members' needs. Social presence, describing levels of social affordance of computer-mediated communication channels, enables the social identification and bond process. Previous research on attachment theory found empirical evidence for social bonding assume that adults, like children, will be most likely to thrive when they have close relationship partners who are responsive to their needs and deeply invested in their welfare [23,24].

Likewise, a small number of experimental studies show that the actual or symbolic presence of a close relationship partner can reduce threat appraisals in adults. For example, holding the hand of an intimate partner attenuated threat-related brain activity in response to mild electric shocks and reduced perceptions of pain in response to heat stimuli. These studies provide some causal evidence for the social regulation of security in adults, but they fail to distinguish between partner presence and partner responsiveness. A closer inspection of the findings, however, suggests that responsiveness may have played a key role in shaping these effects. For example, the threat attenuating effects of hand-holding were strongest for those in high quality relationships [25].

These findings suggest that the beneficial effects of social presence depend in large part on the degree to which a partner is likely to be supportive and responsive to one's needs. Thus, we posit that:

H3a: Social presence will positive influence common identity attachment.

H3b: Social presence will positive influence common bond attachment. 


\section{Relationship between Attachment and Continuance Intention}

According to Hogg (1992) [26], people who are attached to a group evaluate their group more positively than those who are less attached, stay in the group longer, participate more, and exert more effort on its behalf. Likewise, commitment to an organization is associated with lower turnover or intention to leave [27]. In volunteer services for AIDS patients situation, people who reported stronger attachment to the AIDS community participated in a wider range of activities, such as attending AIDS fundraising events, being involved in AIDS activism, and donating to AIDS groups [28].

Kyle et al., (2004) [29] noted that attachment is conceptually similar to psychological commitment. They argued that commonality is evidenced in the dimensions underlying each construct.We thus posit that increased attachment in an online community, whatever the source of that attachment, will lead to a set of visible behaviors such as longer duration of membership, more frequent visits, and more active participation [30] [16]. The literature also suggests that identity-based and bond-based attachment may have some different consequences, especially in relation to members' attitudes toward the group or individuals to whom they have become attached [16]. In particular, identity-based attachment should cause members to attend to and like the group, which in turn will increase their willingness to exert effort to help the group. By contrast, bond-based attachment should cause members to focus on individual relationships with one another, which in turn will increase their willingness to exert effort to help individuals. Thus, we hypothesize that:

\section{H4a: Common Identity Attachment will positive influence continuance intention.}

\section{H4b: Common Bond Attachment will positive influence continuance intention.}

\section{Research Methodology}

\section{Sample and Data Collection}

Cross-border e-commerce platforms, such as ebay, Amazon and Ali express, link users to e-vendors, however, these platforms differ based on aspects such as informational/interactional channels, privacy policies, quality/quantity of peer contents generation, economic feasibility, size, and reputation [31].

We used Ali Epress as the target platform, which has about 500 million registered users on its panel and it is the largest e-commerce platform in China[32]. According to a survey conducted by CNNIC in March 2017, 63.4\% of Internet users in China are of 18-30 years old and 41\% have a bachelor's degree or above. Based on the overall characteristics of Internet users in China, our survey mainly aimed at adults. It was conducted through an online survey website (www.sojump.com). A total of 1200 questionnaires were collected, and after eliminating those with incomplete information, 908 samples were used for this empirical analysis. A representing $76.66 \%$ response rate.

\section{Measures}

To measure the constructs in the research model, model, validated items by other researchers in the extant literature were adapted and multi-item scales were used. All items were modified to fit the cross-border e-commerce applications context. To measure interactivity were based on those of Hoemer (1999) [33]. The items for perceived value was derived from Sweeny and Soutar (2001) [10]. Social presence was measured by the items from Animesh et al. (2011) [34]. Common identity attachment and common bond attachment items were adapted from Prentice et al. (1994) [35]. Continuance intention were borrowed from the study by Shen and Chiou (2010) [36] and Zeithaml et al. (1996) [37]. Thus, a total of thiry-seven items was used to measure the constructs. For each item, a seven-point Likert scale ranging from " $1=$ strongly disagree" to " $7=$ strongly agree."

\section{Analysis}

Following procedures recommended by [38], this research conducted two analysis phases. First, the 
measurement model is estimated with confirmatory factor analysis (CFA) to test reliabilities and validities of the research constructs. Then, the structure model is used to test the strength and direction of the proposed relationships between researches constructs.

\section{Measurement Model}

To avoid common method variance problem or reduce its occurring, this research uses the methods developed by [39]. Harman's single-factor test was conducted [40]. This test assumes that if the common method variance exists, then when all of the variables entered together, they will load on one single factor that will account for all of the variance, or one factor will account for a majority of the variance. This study performed the exploratory factor analysis (EFA) and four factors with eigenvalue greater than one emerged. All 42 items of the total variance was less than $50 \%$. In addition, this study also performed the confirmatory factor analysis (CFA) with all 42 items in the questionnaire. The model fit of the single-factor test was worse (Chi-square $=6521.104$, D.F. $=629$, GFI=0.479, AGFI=0.418, IFI=0.318, CFI=0.315, RMSR=0.164) compared with the model fit of the proposed model (Chi-square=949.083, D.F. $=605$, GFI=0.892, AGFI=0.873, IFI=0.960, CFI=0.960, $\mathrm{RMSR}=0.074$ ). The results indicate that CMV is not a significant problem in this research.

Results also support for the convergent and discriminant validity. As evidence of convergent validity, each item loaded significantly on its respective construct [41]. Evidence of discriminant validity exists when the square root of the average of variance extracted (AVE) in each construct exceeds the coefficients representing its correlation with other constructs [42]. As presented in Table 1 , the results indicate adequate discriminant validity.

Table 1. Discriminant Analysis for Constructs

\begin{tabular}{|c|c|c|c|c|c|c|c|c|c|c|c|c|}
\hline Constructs & MI & II & $\mathrm{FV}$ & EV & SV & MV & SP & CIA & CBA & CI & $\mathrm{CR}$ & AVE \\
\hline MI & 0.812 & & & & & & & & & & 0.896 & 0.660 \\
\hline II & $\begin{array}{l}0.311 \\
* *\end{array}$ & 0.850 & & & & & & & & & 0.912 & 0.722 \\
\hline FV & $\begin{array}{l}0.149 \\
* *\end{array}$ & $\begin{array}{l}0.152 \\
* *\end{array}$ & 0.807 & & & & & & & & 0.882 & 0.652 \\
\hline EV & $\begin{array}{l}0.150 \\
* *\end{array}$ & $\begin{array}{l}0.177 \\
* *\end{array}$ & $\begin{array}{l}0.217 \\
* *\end{array}$ & 0.875 & & & & & & & 0.928 & 0.765 \\
\hline SV & $\begin{array}{l}0.215 \\
* *\end{array}$ & $\begin{array}{l}0.164 \\
* *\end{array}$ & $\begin{array}{l}0.183 \\
* *\end{array}$ & $\begin{array}{l}0.213^{*} \\
*\end{array}$ & 0.860 & & & & & & 0.914 & 0.759 \\
\hline MV & $\begin{array}{l}0.215 \\
* *\end{array}$ & $\begin{array}{l}0.164 \\
* *\end{array}$ & $\begin{array}{l}0.183 \\
* *\end{array}$ & $\begin{array}{l}0.213^{*} \\
*\end{array}$ & $\begin{array}{l}0.311 \\
* *\end{array}$ & 0.834 & & & & & 0.881 & 0.721 \\
\hline SP & $\begin{array}{l}0.196 \\
* *\end{array}$ & $\begin{array}{l}0.210 \\
* *\end{array}$ & $\begin{array}{l}0.174 \\
* *\end{array}$ & $\begin{array}{l}0.243^{*} \\
*\end{array}$ & $\begin{array}{l}0,226 \\
* *\end{array}$ & $\begin{array}{l}0.322 * \\
*\end{array}$ & 0.785 & & & & 0.853 & 0.659 \\
\hline CIA & $\begin{array}{l}0.267 \\
* *\end{array}$ & $\begin{array}{l}0.314 \\
* *\end{array}$ & $\begin{array}{l}0.224 \\
* *\end{array}$ & $\begin{array}{l}0.271 * \\
*\end{array}$ & $\begin{array}{l}0,213 \\
* *\end{array}$ & $\begin{array}{l}0.294 * \\
*\end{array}$ & $\begin{array}{l}0.254 \\
* *\end{array}$ & 0.838 & & & 0.913 & 0.636 \\
\hline CBA & $\begin{array}{l}0.171 \\
* *\end{array}$ & $\begin{array}{l}0.179 \\
* *\end{array}$ & $\begin{array}{l}0.168 \\
* *\end{array}$ & $\begin{array}{l}0.244 * \\
*\end{array}$ & $\begin{array}{l}0.221 \\
* *\end{array}$ & $\begin{array}{l}0.274 * \\
*\end{array}$ & $\begin{array}{l}0.277 \\
* *\end{array}$ & $\begin{array}{l}0.366^{*} \\
*\end{array}$ & 0.879 & & 0.827 & 0.614 \\
\hline CI & $\begin{array}{l}0.280 \\
* *\end{array}$ & $\begin{array}{l}0.285 \\
* *\end{array}$ & $\begin{array}{l}0.169 \\
* *\end{array}$ & $\begin{array}{l}0.225^{*} \\
*\end{array}$ & $\begin{array}{l}0.104 \\
* *\end{array}$ & $\begin{array}{l}0.267 * \\
*\end{array}$ & $\begin{array}{l}0.266 \\
* *\end{array}$ & $\begin{array}{l}0.189 * \\
*\end{array}$ & $\begin{array}{l}0.225^{*} \\
*\end{array}$ & 0.846 & 0.840 & 0.636 \\
\hline $\begin{array}{l}\text { Cronbach's } \\
\alpha\end{array}$ & 0.874 & 0.912 & 0.876 & 0.926 & 0.825 & 0.850 & 0.910 & 0.814 & 0.838 & 0.935 & & \\
\hline
\end{tabular}

Note: MI: Machine Interaction; II: Interpersonal Interaction; FV: Functional Value; SV: Social Value; EV: Emotional Value; MV: Monetary Value; SP: Social Presence; CIA: Common Identity Attachment; CBA: Common Bond Attachment; CI: Continuance Intetntion; CR: Composite Reliability; AVE: Average Variance Extracted; Diagonal value is the square root of AVE; Lower triangle value is the Pearson correlation coefficient.

$*_{p}<0.05 ; * *_{p}<0.01 ; * * * p<0.001$

\section{Structural Model}

We next analyzed the structural model to examine the significance and strength of relationships of each of our hypothesized effects. The structural model provided evidence of a good model fit: $\chi 2=949.083$, D.F. $=605, \chi 2 / \mathrm{DF}=1.569, \mathrm{GFI}=0.891, \mathrm{AGFI}=0.873, \mathrm{RMSR}=0.054, \mathrm{RMSEA}=0.037$. Based on the suggestions of [43] and [44], the criteria of model-fit of this model would be adequate. Overall, the measurement model showed adequate fit. Fig. 1 shows that the hypotheses results and path coefficients. All hypotheses are supported with all path coefficients, $p<0.001$. 


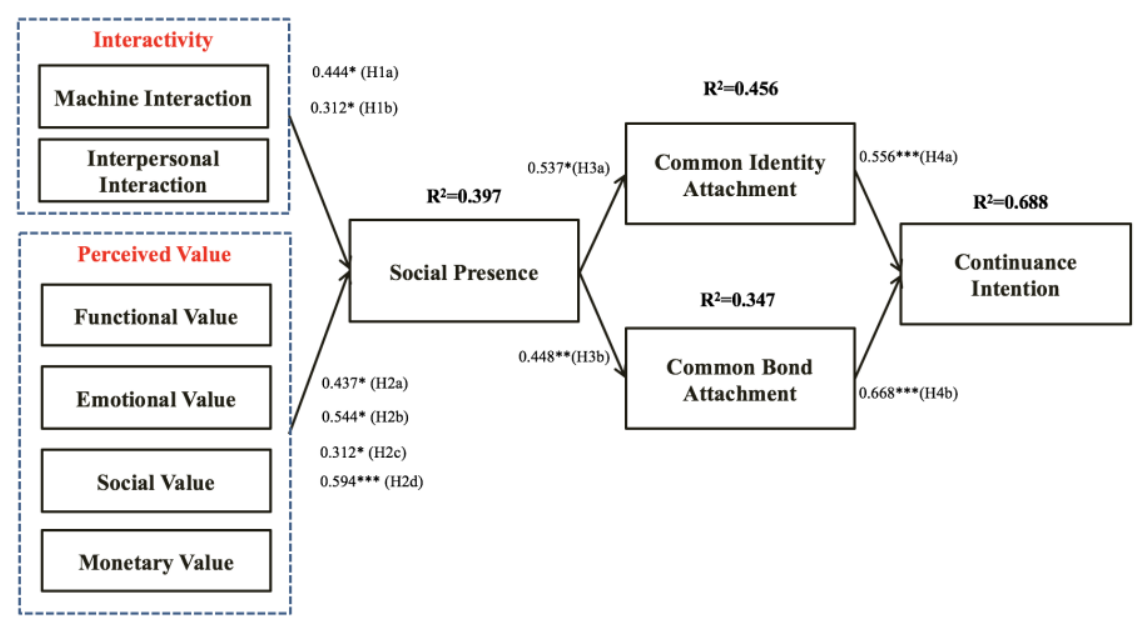

Fig. 1. Results of the structural model. ${ }^{*} p<0.1 ; * * p<0.05 ; * * * p<0.001$

\section{Discussion and Implications}

\section{Discussion}

This study is one of the very first studies which attempts to explain collective behavior in cross-border e-commerce applications using intentional social action. Over the past two decades, IS researchers have demonstrated considerable interest in measuring personal intentions in traditional information systems adoption where the usage experience does not depend on other users [45] . In online social networking sites in contrast, social interaction and connection is the objective. These social communities give everyone a place to share their personal stories, in words, pictures, and videos with their friends. They also connect people with friends and others who work, study, and live around them. They help people learn more about events, parties, and other social functions.

The results of this study is that interactivity, function value, emotional value, social value and monetary value significantly affect social presence. They demonstrate that how the characteristics of cross-border e-commerce account are designed to interact with users and how communication in enabled by those characteristics are important in forming social presence. The more that these communications included rich cues such as VR, photographs, and communication interaction, the more participants felt social presence in the corporate cross-border e-commerce account but through the general interactivity embedded in the form design, indicating that mutual interaction is possible at a personal level and can enable interactions even with external resources. The human service component is the key ingredient for retaining customers to an online retailer. Thus, Social presence in e-commerce gives customers a better experience that resembles a physical store.

Social presence is the most important factor that determines users' usage of cross-border e-commerce applications. The features of social presence indeed can also encourage communities' users to collaborate and work together. In addition, the result indicate that social presence indeed affects cross-border e-commerce users' trust and their perceptions of the satisfaction in a company and that those two constructs affects cross-border e-commerce users' commitment to the company. In this article, we show how insights from group identity and interpersonal bonds theories can be leveraged to increase member attachment in cross-border e-commerce community design. Following the review by Ren et al. (2007), we summarize these antecedents next and present our hypotheses of how their implementations can increase attachment in cross-border e-commerce communities.

In parallel. This research also offers interesting new prospects for marketing managers in term of how to lead e-commerce management in order to obtain better consumer shopping experiences.

\section{Theoretical and Managerial Implications}

This study accomplishes several theoretical objectives. We develop a theoretical model to explain how these features would influence participants' intention to purchase cross-border e-commerce goods. 
First, this result revealed that interpersonal interaction on cross-border e-commerce community positively influences the perceptions in terms of social presence.Second, the customers' perceived value is often deemed as the key factor most drastically influencing the behavioral outcome in the course of decision-making of purchase. The customers' assessment before purchase, continual use after purchase or the value perceived via customers will all further influence the future purchase intention. Third, this research results found that social presence has positive effect on common identity attachment and common bond attachment. According to the opinions of[1], this study classified perceived value into function value, emotional value, social value and money value mainly in that the application for these four dimensions is wider and they are consistent in nature. Besides, by adopting such value classification method, it can also fully reflect the value brought by cross-border e-commerce to customers.

While the influence of social presence in various cross-border e-commerce environments has been previously investigated, relatively few studies have examined how corporate cross-border e-commerce company interact with users. Our findings show that in this context, the values that induce consumers' relationships with companies can stem from and be increased by social drives, demonstrating that users' perceptions of how trustworthy and satisfaction companies are and how useful their information are dependent on the way corporate cross-border e-commerce accounts build the feeling of social presence through using inherent characteristics of cross-border e-commerce.

Fourth, the findings for the cross-border e-commerce study, the research result shows that satisfaction and trust can significantly positively influence affective commitment and calculative commitment. Satisfaction has the greatest influence on both of the antecedent factors of affective commitment and calculative commitment. It shows that the better satisfaction the users feel over the service provided by cross-border e-commerce account can better obtain the users' attachment and affective identity.

Company marketers can most effectively design communications with consumers through cross-border e-commerce. The operations of person interactivity suggest that display in the history of the footage of particular conversations and broadcasting other users' messages is a good way to show users that corporate cross-border e-commerce accounts value the conversation and that other people are also engaged in it.

Finally, our result suggests that higher alternative attractiveness lead to higher calculative commitment toward a e-commerce company. This result can be explained through the lens of the cross-border purchase context. Unlike regular purchased products, cross-border purchases require a significant amount of monetary and emotional resource allocation for most customers. Hence Once bought, a customer may wait for a comparatively longer period for his or her net purchase. The customer may increase his commitment to the cross-border e-commerce company by advocating the company strongly. This strategy, in turn, may make his consumption appropriate in the eyes of the significant others.

These results thus have extremely important managerial implications because they suggest that, if brands want to create loyal customers, they need to work better on their communications as well as of the entire brand experience in order to generate and consolidate affective bonds with customers.

The brand management needs to be the focus of the entire organization and that it will be extremely difficulty to build superior experiences and the customers' commitment.

\section{Limitations and Future Research}

First, although both initial relationship building and relationship maintenance are critical to managing effective corporate communications, it is difficult to capture a continued relationship with fictitious companies created for an experiment. Second, In terms of abstract subjects, it is suggested to increase the node of network questionnaire distribution, to design the inducement for filling and to increase the investigation on preference in the behavior of downloading and purchase, downloading or purchase category and degree of willingness to pay for it, aimed at users of cross-border e-commerce account with different characteristics. Thus, the influence of relevant factors and behavioral intention can be understood and comparative analysis can be conducted with this research, so as to seek for the more 
reliable argumentation. Third, it is suggested to further discuss their influence factors in the future research, such as benefits, appropriateness of technology or product involvement. We hope that future research will investigate these issues in the area. Therefore, future research might conduct longitudinal studies to mimic real cross-border e-commerce environments in which participants can continue their relationships with real corporate cross-border e-commerce accounts.

\section{Conclusions}

This study makes several important contributions to develop insights for cross-border e-commerce community design. Our theory-inspired design approach provides a practical lens through which designers and managers can look at their decisions in a nuanced and systematic manner, rather than using overly general themes of sociality or through trial and error. We believe that theoretical insights supported by empirical evidence are powerful tools that designers and managers could leverage to build cross-border e-commerce communities. They will still need to make important choices to customize the design features to fit the technology being used, the class of members, and other particulars that may shape member experience. When it comes to design, there are often no correct answers, only wise tradeoffs among alternatives. However, our theory inspired approach should help designers and managers constrain and navigate the design space they need to explore.

\section{Acknowledgement}

This research was financially supported by the Collaborative Innovation Center of China Pilot Reform Exploration and Assessment-Hubei Sub-Center' Research Foundation.

\section{References}

[1] M. J. Schuemie, P. van der Straaten, M. Krijn, C. A. van der Mast, Research on presence in virtual reality: a survey, CyberPsychol Behav. (4:2) (2001) 183-201.

[2] Y. Jung, Understanding the role of sense of presence and perceived autonomy in users' continued use of social virtual worlds, J Comput Med Commun (16:4)(2011) 492-510

[3] T. G. Plante, A. Aldridge,R. Bogden, C. Hanelin, Might virtual reality promote the mood benefits of exercise? Comput Hum Behav. (19:4)(2003) 495-509

[4] C. J. Keng, T. L. Huand, L. C. Cheng, M. K. Hsu,Modeling service encounters andcustomer experiential value in retailing: an empirical investigation of shopping mall customers in Taiwan, Int J Serv Ind Manag.(18:4)(2007) 349-67

[5] J. Steuer, Defining virtual reality: dimensions determiningtelepresence, J Commun.(42:4)(1992) 73-93

[6] A. Animesh,A. Pinsonneault, S. B. Yang, W. Oh, An odyssey intovirtual worlds: exploring the impacts of technological and spatialenvironments on intention to purchase virtual products, Manag Inf Syst Q. (35:3)(2011) 789

[7] N. Suntornpithug, J. Khamalah, Machine and person interactivity:the driving forces behind influences on consumers' willingnessto purchase online, J Electron Commer Res.(11:4)(2010) 299325

[8] D. L. Hoffman, T. P. Novak,Marketing in hypermedia computer-mediatedenvironments: conceptual foundations, J Mark.(60:3)(1996) 50-68.

[9] H. J. Schau, M. C. Gilly, We are what we post? Self-presentation in personal webspace, J. Consumer Res. (30:3)(2003) 385-404. 
[10] J. C. Sweeny, G. N. Soutar, Consumers perceived value: The development of a multiple item scale, J. Ret.(77:2)(2001) 203-220.

[11] E. Williams, Experimental comparisons of face-to-face and mediated communication: A review,Psychol Bull.(84:5)(1997) 963-976.

[12] J. Fulk, C. W. Steinfield, J. Schmitz, J. G. Power, A social information processing model of media use in organizations, Commun Res. (14:5)(1987) 529-552.

[13]M. E. Zaglia, Brand communities embedded in social networks,J Bus Res.(66:2)(2013), 216223.

[14]Z. Zhou, Q. Zhang, C. Su, N. Zhou, How do brand communitiesgenerate brand relationships? Intermediate mechanisms,J Bus Res.(65:7)(2012), 890-895

[15]Y. Ren, R. E. Kraut, A simulation for designing online community:Member motivation, contribution, and discussion moderation, Inf Sys Res. (2011)

[16] Y. Ren, R. Kraut, S. Kiesler, Applying common identity and bondtheory to design of online communities, Organ Stu. (28:3)(2007), 377-408.

[17]A. Bhattacherjee, Understanding information systems continuance:an expectation-confirmation model,Manag Inf Syst Q.(25:3)(2001a)351-370.

[18]F. D. Davis, F. D. Perceived usefulness, perceived ease of use, and user acceptance of information technology,Manag Inf Syst Q.(13:3)(1989)319-340

[19]O. Kwon, Y. Wen, An empirical study of the factorsaffecting social network service use,Comput Hum Behav.(26:2)(2010), 254-263.

[20]Y. Kang, H. Lee, Understanding the role of an it artifact in online service continuance: an extended perspective of user satisfaction,Comput Hum Behav.26(3)(2010), 353-364.

[21]J. Short, E. Williams, B. Christie, Theoretical approaches to differences between media. The social psychology of telecommunication (pp. 61-76). Wiley, New York, 1976.

[22]A. J. Flanagin, M. J. Metzger, Internet use in the contemporary media environment, Hum Commun Res. (27:1)(2001) 153-181.

[23]J. Bowlby, Attachment and lossAttachment, Vol. 1, Basic Books, New York, 1969.

[24] J. T. Cacioppo, W. Patrick, Loneliness: Human nature and the need for socialconnection. Norton \& Company, New York, 2008.

[25]J. A. Coan, H. S. Schaefer, R. J. Davidson, Lending a hand: Social regulation ofthe neural response to threat. Psychol Sci.17(2006) 1032-1039.

[26] M. A. Hogg, The Social Psychology of Group Cohesiveness: From Attraction to Social Identity, HarvesterWheatsheaf, London, 1992.

[27]J. Meyer, D. Stanley, L. Herscovitch, L. Topolnytsky,Affective, Continuance, and Normative Commitment to the Organization: A Meta-Analysis of Antecedents, Correlates, and Consequences, J Voc Behav. (61:1)(2002), 20-52.

[28] A. M. Omoto, M. Snyder, Considerations of Community: The Context and Process of Volunteerism,Am Behav Sci.(45:5)(2002) 846-867.

[29]G. T. Kyle, A. J. Mowen, M. Tarrant,Linking Place Preferences with Place Meaning: An Examination of Relationship between Place Motivation and Place Attachment,J Environ Psychol (24:4)(2004) 439-54. 
[30]A. Blanchard, M. L. Markus, The Experienced 'Sense' of a Virtual Community: Characteristics and Processes, The Data Base for Adv in Inf Sys. (35:1)(2004) 65-79.

[31]N. J. Allen, J. P. Meyer, The measurement and antecedents of affective, continuance and normative commitment to organization,J Occup Organ Psychol.(63:1)(1990) 1-8.

[32] Y. Fan, J. Ju, M, Xiao, Reputation premium and reputation management: Evidence from the largest e-commerce platform in China, Inter J Indus Organ. 46(2016), 63-76.

[33] J. Hoerner, Scaling the Web: A parasocial interaction scale for WorldWide Web Sites, in D. W. Schumann, E. Thorson (Eds.), Advertising and theWorld Wide Web, Lawrence Erlbaum Associates, Upper Saddle River, New York, 1999.

[34] A. Animesh, A. Pinsonneault, S. B. Yang, W. Oh, An odyssey into virtual worlds: Exploring the impacts of technological and spatial environments on intention to purchase virtual products,Manag Inf Syst Q. (35:3)(2011) 789-810.

[35]D. A. Prentice, D. T. Miller, J. R. Lightdale, Asymmetries in attachment of groups and to their members: Distinguishing between c/ommon-identity and common-bond groups,Pers Soc Psychol Bull. (20:5)(1994) 484-493.

[36] C. C. Shen, J. S. Chiou, The effect of community identification on attitude andintention toward a blogging community, Inter Res. (19:4) 2010, 393-407.

[37] V. Zeithaml, L. Berry, A. Parasuraman, The behavioral consequences of servicequality,J Mark.60(1996) 31-46.

[38]R. Agarwal, V. Venkatesh, Assessing a firm's web presence: a heuristic evaluation procedure for the measurement of usability. Inf Syst Res.(13:2)(2002), 168-186.

[39]P. M. Podsakoff, S. B. MacKenzie, J. Y. Lee, N. P. Podsakoff, Common method biases in behavioral research: A critical review of the literature and recommened remedies,J Appl Psychol $(88: 5)(2003)$ 879-903.

[40]P. M. Podsakoff, D. W, Organ, Self reports in organizational research: Problems and prospects. J Manag,(12:4)(1986) 531-544.

[41] J. C. Anderson, D. W. Gerbing, Structural Equation Modeling in practice: A review and recommended two-step approach,Psychol Bull.(103:3)(1988) 411-423.

[42] C. Fornell, D. F. Larcker, Evaluating structural equation models with unobservable variables and measurement error,J Mark Res.(18:1)(1981) 39-50.

[43] K. G. Jöreskog, D. S. Sörbom,LISREL 8, A Guide to the Program and Application. Chicago: SPSS Inc, Chicago, 1993.

[44] J. F. Jr. Hair, W. C. Black, B. J. Babin, R. E. Anderson,Multivariate Data Analysis (7th ed.). Englewood Cliffs: Prentice-Hall, Englewood Cliffs, 2010.

[45] F. D. Davis, R. Bagozzi, P. R. Warshaw, User acceptance of computer technology: A comparison of two theoretical models,Manag Sci.(35:8)(1989) 982-1003. 